\title{
Ma Carmen lópez Sáenz y Beatriz Penas Ibáñez (eds.) \\ PARADOJAS DE LA INTERCULTURALIDAD. \\ FILOSOFÍA, LENGUAJE Y DISCURSO. \\ MADRID, BiblioteCA NUEVA, 2008, 223 PP.
}

por Luis Álvarez Falcón

En 1705 , en su célebre trabajo Nouveaux essais sur I'entendement humain, en respuesta a la prestigiosa obra de John Locke, un Filatetes, amigo acérrimo de la verdad, y un Teófilo, amante abnegado de Dios, mantendrán un diálogo ejemplar para la historia del pensamiento moderno. En sus líneas advertiremos el germen inconcluso de un problema crucial en todos los ámbitos del conocimiento humano: la naturaleza del principio de «Identidad». Al tratar del principio y de su aplicación, el primer contertulio confirmará el problema: "Más bien me parece que el principio general supone la negación particular y que esta última constituye el fundamento de aquél. Pues la proposición: «lo que es lo mismo no es diferente» es aún más fácil de comprender que el principio general de contradicción". A tan destacada afirmación, responderá Leibniz en palabras de Teófilo: "No comprendo cómo la proposición: «lo mismo es lo diferente» haya de ser el origen del principio de contradicción y más comprensible que él, pues a mí me parece que obramos más libremente al decir que $A$ no es $B$ que al decir que $A$ no es no-A. Y la razón de que $A$ no sea $B$ estriba en que $B$ contiene en sí la nota no- $A^{\prime \prime}$. La antigua querella sobre «identidad» $y$ «diferencia»

1 Leibniz, G. W. Sämtliche Schriften und Briefe. Herausgegeben von der Deutschen Akademie der Wissenschaften zu Berlin. Sechste Reihe. Philosophischen Schriften. Sechster Band. Akademie Verlag, Berlin 1962. Traducción española: Nuevo tratado sobre el enten-dimiento humano, Ed. Aguilar, Buenos Aires 1980; p. 80. 
quedará así expuesta, esta vez en sus términos lógicos, pero anunciando lo que será un itinerario preciso de deriva hacia el compromiso ontológico, moral y político. Ya en el Sofista, Teeteto había denunciado el temor de que el «no-ser» estuviera entrelazado con el «ser» mediante una symploké o combinación. Tal polémica será el origen de una inagotable discusión sobre la naturaleza y límites de la «identidad» ante la irreductible multiplicidad de los fenómenos, cuestión ineludible que estimará el alcance y las inevitables tendencias de la razón en su aspiración hacia lo incondicionado. Tal escollo irá siendo permanentemente articulado a lo largo de la historia del pensamiento, afectando a todas las instituciones simbólicas racionales (ciencia, religión, moral, política, arte o filosofía), modulándose a tenor de los fenómenos exhibidos y abordados, salvando el modo de ser de las apariencias y mostrando los dinamismos propios del conocimiento en su intento de comprensión de la realidad histórica.

A partir del Idealismo y del Romanticismo alemán, y tras los puntos de inflexión de algunos autores como Schopenhauer y Nietzsche, las diferentes modulaciones del principio de «identidad» van a exhibirse con especial ostensión en el pensamiento del siglo $X X$, desde los planteamientos fenomenológicos hasta las propuestas críticas, analíticas, sociológicas o antropológicas. Pensadores de la talla de Edmund Husserl, Maurice Merleau-Ponty, Claude Lévi-Strauss, Adorno, Deleuze, Foucault, J. P. Sartre, Patoĉka, Goffman, Habermas, Althusser, Paul Ricoeur, Judith Butler o M. M. Bajtin, entre otros, han ido enlazando un discurso que, paulatinamente, se ha ido adecuando a la exhibición patente de los fenómenos contemporáneos. Las nuevas concepciones antropológicas del ser humano, la dinámica de los procesos culturales, la transformación progresiva del mundo de la vida; la intersubjetividad y la comunicación, la naturaleza del género en un contexto intercultural, el fundamentalismo, el análisis crítico del discurso; la performatividad lingüística y su papel en la formación de la identidad, la construcción narrativa de estas identidades, el cambio de paradigma lingüístico-filológico y la formación discursiva de las identidades y del sentido, etc., serán algunos de los problemas que hacen ostensible la necesaria modulación de los contextos teóricos ante la manifestación de los fenómenos más patentes. Esto 
es lo que Ma Carmen López Sáenz y Beatriz Penas Ibáñez nos muestran en una perfecta compilación de diversos trabajos de investigación que lleva por título el paradójico rótulo: Paradojas de la interculturalidad. Filosofía, lenguaje y discurso ${ }^{2}$, y que la prestigiosa Editorial Biblioteca Nueva publica en su colección Razón y Sociedad, dirigida por Jacobo Muñoz.

Tres son los ejes de articulación de un discurso que, en principio, parte de un problema común y de una misma evidencia fáctica: la paradójica relación entre identidad y diversidad en el contexto de un diálogo intercultural. De ahí que la propuesta, además de ser novedosa en su presentación, quede construida ejemplarmente sobre el rigor de un triángulo conceptual, en el que se desplegarán progresivamente las diferentes aproximaciones transdisciplinares, y cuyos vértices designan tres núcleos críticos de discusión: diálogo, conflicto y discurso, es decir, del "yo" a los "otros", del "yo" frente a los "otros" y del "yo" en los "otros", y todo de un modo quiasmático en su propia viceversi-

${ }^{2}$ López Sáenz, Ma. C., Penas Ibáñez, B. (Eds.) Paradojas de la interculturalidad. Filosofía, lenguaje y discurso, Editorial Biblioteca Nueva, S. L. , Madrid 2008. dad. Tal escuadra pondrá en juego tanto las consideraciones antropológicas como las consideraciones ontológicas, epistemológicas, sociales, morales y políticas, sirviendo de matriz para el desarrollo de las más potentes intuiciones entorno al problema de la intersubjetividad, de la comunicación, y de la historia en tanto institución simbólica. A su vez, este triángulo paradójico y expositivo se desplegará en nueve paradas, cuyos desarrollos teóricos darán unidad y consistencia al subtítulo de este compendio: filosofía, lenguaje y discurso. Algunas de estas reflexiones ya habían sido adelantadas por algunas autoras y autores en el contexto de Interculturalism. Between Identity and Diversity ${ }^{3}$. Sin embargo. La novedad de esta obra no sólo radica en las nuevas aportaciones (las de Ma Carmen López, Celia Amorós y Jesús M. Díaz), sino también en la necesaria traducción del resto a nuestro idioma, así como en la unidad paratáctica de sus contribuciones y en la posibilidad de reflexión que abre la contigüidad de sus aspectos comunes. De este modo, su lectura no sólo se hace fluida

${ }^{3}$ López Sáenz, Ma. C., Penas Ibáñez, B. (Eds.) Interculturalism. Between Identity and Diversity, Peter Lang, Nueva YorkBerna 2006. 
sino que, además, permite un ir $y$ venir entre las diferentes propuestas, y, lo que es más importante, una conclusión cooperada y favorecida por la proximidad de los problemas; de tal manera, que nos hará recordar aquella máxima que Walter Benjamin enunció en sus Cuestiones preliminares de crítica del conocimiento, al comparar las ideas con las madres faústicas. La recolección de los fenómenos incumbe a los conceptos, y la división que en ellos se efectúa consigue de un golpe un doble resultado: por un lado, la salvación de los fenómenos; por otro lado, la manifestación de las ideas ${ }^{4}$.

Así, pues, y después de una esclarecedora introducción de las coeditoras a los aspectos filosóficos y discursivos de esta problemática actual, Ma Carmen López Sáenz nos conducirá de nuevo al enigmático concepto Merleau-pontiano de Chair, para mostrarnos las posibilidades que el autor hizo patentes en su perspectiva fenomenológica, a través de tres ejes o pivotes principales: la circulación intersubjetiva,

4 Benjamin, W. Ursprung des deutschen Trauerspiels, ed. R. Tiedemann, Suhrkamp Verlag, Frankfurt am Main 1963. Traducción española: El origen del drama barroco alemán. Trad. José Muñoz Millanes, Taurus, Madrid 1990; pp. 9-41. las apercepciones de lengua y la reesquematización en lenguaje de esquematismos de fenomenalización, y el registro simbólico de la Historia como Stiftung o institución. Por otro lado, Javier San Martín pondrá el acento en la ontología de la Lebenswelt, dando continuidad a la propuesta anterior desde el singular contexto de Die Krisis der europäischen Wissenschaften und die transzendentale Phänomenologie, Einleitung in die Phänomenologische Philosophie. Y, por último, y en este mismo vértice del diálogo, del "yo" al "otro", Karina Trilles retomará a Merleau-Ponty para caracterizar el pensamiento del autor como una fenomenología de la palabra intersubjetiva, recordando claramente al Merleau-Ponty de La prose du monde.

Sin embargo, en el segundo vértice de nuestro diedro, encontraremos el "conflicto", el encuentro del "yo" frente a los "otros". Es ahí donde, en clara alusión a la complejidad de un nuevo factum, el estado del género, el fundamentalismo religioso, y el análisis crítico del discurso se presenten como expresiones de una dialéctica cuyo marco multicultural presenta las claves de un conflicto secular. De este modo, Celia Amorós expondrá la necesidad 
crítica de un "sujeto real" que responda a la dinámica de la cultura, en el marco de un antagonismo hostil que exhibe una regresión interesada de la naturaleza misma del sujeto en su devenir histórico. Del mismo modo, Jesús M. Díaz, desde el mismo fundamento de esta regresión, la saturación por sobredeterminación de la naturaleza de la «Identidad», expondrá brillantemente la desmesura o hipertrofia del sentido que caracteriza a la actitud fundamentalista, en clara resonancia con el discurso de Amorós y con la fundamentación fenomenológica expuesta en la primera parte de esta compilación. Por último, la intervención de Jef Verschueren pondrá en evidencia la inversión de la naturaleza misma de la «tolerancia», como el "todo vale" de una sociedad caracterizada por la confusión y que prodiga la cultura del "barbitúrico" como muestra de su propia incapacidad acrítica y unidimensional.

Para finalizar, el último vértice de este triángulo vendrá dado por el problema del "discurso", del "yo" en los "otros", y, por supuesto, de los "otros" en el "yo". La función del discurso en la formación de identidades pondrá en juego una especial concepción hermenéutica que gene- ra identidad en la propia construcción de sus significaciones. De este modo, Elvira Burgos Díaz nos traerá de nuevo su exégesis butleriana, mostrando el punto de partida de la autora de Excitable Speech. A politics of the Performative. Frente al esencialismo y al constructivismo, el concepto de «performatividad», entre Althusser y Foucault, nos conducirá a la cuestión definitiva: la aplicación de esta «performatividad»al ámbito de la lingüística y su compromiso en la modulación de la «identidad». La línea de contigüidad quedará trazada por Ángeles de la Concha, quien a partir de la fundamentación butleriana hará un análisis exhaustivo y muy brillante del discurso narrativo de ficción, de tal modo que su exposición, además de ser especialmente ilustrativa, atravesará la obra de Deleuze y Guattari para llegar hasta Brontë, Wollstonecraft, Grosz, o Dora Chance, la heroína bastarda de Niños sabios. Siguiendo esta misma línea de discurso, José Ángel García Landa abordará la misma construcción narrativa del sujeto, pero esta vez como formación discursiva de la identidad, en tanto transmisión de articulaciones sociales. En este sentido, la narrativa contendrá una posibilidad como mecanismo cognitivo, con 
una clara función formativa, en cuanto dinamismo interactivo que genera una dimensión autoformativa de la conciencia crítica. La teoría narrativa del sujeto será una fuente de construcción tanto de identidades como de diferencias. Desde Hume hasta Heidegger o Ricoeur, pasando por la estética de la recepción, sobre todo por Wolfgang Iser, su concepto de "lectura resistente" terminará con el análisis de Kerby en su Narrative and the Self. Y, por útimo, para cerrar este extraño poliedro discursivo, Beatriz Penas Ibáñez, en una excelente exposición del paradigma de la lengua en su perspectiva sociopragmática, rescatará el pensamiento de Bajtin para fundamentar tanto la práctica negativa de un discurso de identidades fijas como la apertura a la creación de identidades interculturales, aproximando la fenomenología y la hermenéutica a la lingüística de este siglo, recuperando a Ricoeur, Halliday, Bourdieu, Von Slagle, Gumperz o Winograd, y reivindicando una postura sociopragmática que, como la autora indica, aúne libertad y responsabilidad con creatividad.

De este modo, el triángulo quedará definitivamente cerrado, pero siempre abierto al devenir temporal según la modulación misma de la naturaleza de la «Identidad». Paradojas de la interculturalidad. Filosofía, lenguaje y discurso, destaca el rigor de una propuesta amplia, clara y abierta, cuyo objetivo último queda perfectamente definido por sus editoras al confirmar que los vértices expuestos, al designar los tres núcleos críticos de esta discusión (diálogo, conflicto y discurso) deben ser definitivamente abordados desde los ángulos de un sólido superior, aquél que es definido por tres potencias irreductibles en el ser humano: pensamiento, memoria e imaginación. Tal como nos recordaba Leibniz al comenzar, la «Identidad» tiene la facultad de modularse, curvándose como una elipse donde se pliegan los fenómenos de cada tiempo, en definitiva, los fenómenos de la humanidad. De este modo, en 1686, en una de sus epístolas a Foucher, el creador de la Academia de Berlín resumió de esta manera la polifonía modulada que ustedes pueden descubrir en la atenta lectura de este ensayo: "No es preciso que lo que nosotros concebimos de las cosas exteriores sea perfectamente semejante a ellas, sino que basta que las exprese como una elipse expresa a un círculo visto de través, de suerte que a cada punto del círculo corresponda uno de la 
elipse y viceversa, según una ley de relación".

Investigaciones Fenomenológicas, n. 8, 2011. 